\title{
Effect of Standard Costing on Profitability of Manufacturing Companies: Study of Edo State Nigeria
}

\author{
Iliemena, Rachael O. ${ }^{1} \quad$ Amedu, Jimoh Michael Adinoyi ${ }^{2}$ \\ 1.Department of Accountancy, Nnamdi Azikiwe University Awka, Nigeria \\ 2.Department of Accountancy, Edo State Polytechnic Usen, Nigeria
}

\begin{abstract}
The study investigated the effect of standard costing on profitability of selected manufacturing companies in Edo state Nigeria. This was achieved through a review of the effect of standard costing system on cost reduction, normal loss and gross profit from production. Extant literatures were reviewed, and three hypotheses developed and tested. The population of the study consisted of selected manufacturing firms in Benin City. In order to generate the necessary data for this study, primary method of data collection was adopted and applied through the administration of a questionnaire designed in a 5-point Likert scale. The formulated hypotheses were tested using Z-Test statistics at 5\% alpha level. Findings generated in this study revealed that there is significant positive effect of standard costing on cost reduction. It was further observed that the more a firm practices standard costing, the more its profit increases. Based on the above findings, we recommend that manufacturing firms should adopt and consistently apply standard costing in their accounting system so as to ensure the efficient use of resources for effective control of costs and enhancement of profitability.
\end{abstract}

Keywords: standard costing, cost reduction, and profitability.

DOI: $10.7176 / \mathrm{JRDM} / 53-03$

Publication date:March $31^{\text {st }} 2019$

\section{INTRODUCTION}

Standard costing is a performance appraisal technique used by comparing actual performance against the standards for all areas of operations with the organization. This is done in discussion with various heads of organization segments (Egbunike, 2014). When actual performance takes place, the actual data are compared with standards; if there is a difference between actual results and standards, the difference is analysed to find reason thereof. Deviation of actual from standard is called 'variance'. Such variance may be 'favourable' or 'Adverse' for the organization. Abdullahi, (2014). Controlling cost involves providing clear cut information on what the cost should be incurred, what the cost was actually incurred, what is the variance between what was and what should have been, why and what remedial action should be taken to ensure that the actual occurrence agree with the planned. Standard costing is a measure of comparison for quantity and qualitative values. It is a normal reference point for revaluation of performance. It has also been variously referred to as the preparation and the use of standard cost and measurement at the points of incidence Okoye, (2000). Standard costing is concerned with measures of efficiency, which describes how managers can have control over the acquisition and use of resources in producing a given quality of output.

The survival of contemporary manufacturing concerns in Nigerian 21 st century can be said to largely depend on the efficiency of its management. While management efficiency can be measured in a lot of ways including the profitability or reported profit, this can only be achieved through implementation of adequate policies to cut down operating cost.

Standard costing is seen as one of the ways to cut down production cost in manufacturing concerns. This is because, it enables firms to preset target cost of materials and processes while employee are compelled to the cost. This according to Egbunike (2007) enhances productivity, cost minimization and employee efficiency.

However, in spite of the numerous benefits gained by an organization from the use of standard costing technique, this technique for cost control is bedevilled by so many drawbacks, which include: the establishment of a standard that is in most cases unattainable; the problem of identifying the specific needs of consumers; persistent increase in general price level; frequent

changes in the level of technology; political instability and changes in government; changes in macroeconomic policies; problems associated with the accurate estimation of normal loss in the course of production; variation in labor rate per hour among different organizations which depends on other economic variables; and operating managers' negative attitudes towards the established standards (Yoshikawa et al., 1993; Dean, 1948). This therefore necessitates a research to empirically test the effect of standard costing on organisational profitability.

\subsection{Objective of study}

The main objective of the study is to determine the effect of standard costing on profitability of manufacturing companies. 
The specific objectives of the study are;

1. Ascertain the effect of standard costing on cost reduction.

2. Assess the effect of standard costing on gross profit.

3. Determine the extent to which standard costing affect reduction of normal losses.

\subsection{Research Hypotheses}

Ho1: Standard costing has no significant effect on cost reduction.

Ho2: There is no positive effect of standard costing on gross profit.

Ho3: standard costing does not have significant effect in reduction of normal losses.

\subsection{Scope and limitation of study}

The scope of this study only covers selected manufacturing companies in Benin City, the capital of Edo state. The generalisation of the outcome of this study may be hindered by the restrictions of the study to Edo state. Also, getting compliance from employees in filling out the questionnaires posed a major constraint, although this was made up y the researcher by conducting Respondent education, to encourage and incite compliance.

\section{Literature review}

\subsection{Conceptual framework}

\subsubsection{Standard costing}

Standard costing is by Nweze (2010) as a system of accounting which makes use of predetermined costs relating to each element of cost layout, materials and overhead for each line of product manufactured or service supplied. Standard costing technique therefore represents an integral part of management accounting control technique which will also include budgeting system and responsibility accounting statement. Adeniji (2009) states that standard costing represents an integral part of management accounting control techniques which also include budgeting system and responsibility accounting statement. Standard costing technique may be either viewed from the perspective of marginal costing technique or absorption costing technique (Egbunike, 2014). Standard costing often give rise to variance analyses which enables a comparison of the standard costs with the actual costs incurred in the manufacturing process. Adeniji (2004) defined variance as the difference between the standard cost of production and the actual cost of production or the difference between the budgeted revenue and the actual revenue. Rotch and Allen (1982) stated that variance is the deviation of actual from expected. Several factors are responsible for the differences between standard costs and actual costs. These factors are associated with the price of materials, material usage, labour rate, labour efficiency, and overheads. In the implementation of standard costing, management is given the opportunity to practice management by exception which enables management attention to be focused on areas of variances (favourable or unfavourable) depending on the aim and nature of the standard.

\subsubsection{Cost Reduction and profitability}

Cost reduction can be seen as a decrease in cost or increase in cost-saving arising from the better use of resources in the production process. The aim of cost reduction strategy or technique is to utilize opportunities bringing about a saving in material-cost, labour-cost, overhead-expenses, and any other cost arising in a production process. According to the Terminology of the Institute of Cost and Management Accountants London, Cost reduction is to be understood as the success of real and unchanging reduction in the unit costs of goods manufactured without impairing their suitable for the use intended. The necessity for cost reduction arises when the profit margin has to be increased without an increase in the sales turnover i.e. for the same volume of sales, the cost should be reduced. Hence, the principle way of establishing cost consciousness is to minimize cost at all the levels and highlighting the role and responsibility of every employee in every part of the organisation (lawal, 2017). Standard costing happen to be one of the techniques which enhance the attainment of cost reduction as it predetermines the respective costs of material, labour and overhead before the commencement of the production process. With this also comes the benefit of achieving the most with the least cost and reduction of wastages in the course of production. A company can reduce material cost by either using fewer materials in the production process or reduce material prices by utilizing quantity discounts and other trade discounts. The cost of labour can be reduced through elimination of overtime, reduction and where possibly, elimination of idle time and increased supervision and motivation of workers. When cost reduction is achieved, it is always reflected in the profit of the manufacturing company.

\subsubsection{Concept of profitability}

Pandey (2010) defines profit as the difference between revenues and expenses over a period of time, (usually one year). Profit is the ultimate output of a company and it will have no future if it fails to make sufficient profit. Therefore, the financial manager should continuously evaluate the efficiency of the company in terms of profit. A company should earn profit to survive and grow over a long period of time. Ezeamama (2010) agrees that profit is the difference between revenues and expenses over a period of time. Therefore, profitability is the ability to make profits from all business activities of the company, organization, firm or an enterprise. It shows how efficiently 
the management can make profit by using all the resources available in the market. However, the term 'profitability' is an index of efficiency and is regarded as a measure of efficiency and management guide to greater efficiency. The change in operational efficiency is merely one of the factors on which profitability of an enterprise largely depends; moreover, there are many other factors besides efficiency which affects profitability ranging from the degree of competition that a firm faces, market competition, the strength of demand, the state of the demand, the advertising campaign, substitutes, Costing methods to the efficiency of the company. The Companies calculate gross profit by subtracting their manufacturing costs from the revenue generated after sales. Therefore the money difference between the costs of goods sold and net revenue generated represents the gross profit.

\subsection{Theoretical framework}

\subsubsection{Efficiency Structure Theory (ES)}

The ES hypothesis states that firms earn high profits because they are more efficient than others. There are two distinct approaches within the ES; the X-efficiency and scale-efficiency hypothesis. According to the X-efficiency approach, more efficient firms are more profitable since they have lower costs. Such firms tend to gain larger market shares, which may manifest in higher levels on market concentration, but without any causal relationship from concentration to profitability (Athanasoglou et al., 2006). The scale approach emphasizes economies of scale rather than differences in management or production technology. Larger firms can obtain lower unit cost and higher profits through economies of scale. This enables large firms to acquire market share, which may manifest in higher concentration and then profitability.

\subsection{Empirical Review}

Reeve and Philpot (1988) supported that statistical process control is an efficient way in cost control and cost reduction techniques. He said that, defining the process from the point of view of the financial manager is the first step in SPC. More so, over time, the characteristics of the process are measured and observed. Control charting is the process of studying the difference from the mean. This identifies correctly if the process has come up against any special difference that needs better attention. With the use of SPC, firms are able to significantly improve organizational effectiveness, product quality, and process efficiency.

Brancato (1995) and Fisher (1995a) indicate that many firms believe that financial measures are too historical and "backward-looking," lack predictive ability to explain future performance, reward short-term or incorrect behavior, provide little information on root causes or solution problems, and give inadequate consideration too difficult to quantify "intangible", assets such as intellectual capital. As a result, many firms are supplementing financial metrics with a diverse set of non-financial performance measures that are believed to provide better information on strategic progress and success.

Horngren (1991) argue that cost management must not be isolated from other managerial functions and should play a key role in the implementation of the company strategies. It is reported that less than $10 \%$ out of nearly five million finance function professionals in the United States are involved in audit, tax, and external financial reporting. It takes more people to do the work than to check the work. Most people are believed that what an "accountant" does are taxes or working at a CPA firm. The cause of this imbalance is the proliferation of accounting laws and regulation themselves. Looking at the role played by cost management in construction industry, it is reported that in the case of cost estimating in construction industry, the information produced has the additional drawback that it is remotely related to the way costs are incurred.

Salter (1995) suggested that performance measurement of corporate and business unit has three dimensions: (1) effectiveness, (2) efficiency, and (3) adaptability. Some indicators of three dimensions are returns on investment, sales growth, and new product success, respectively.

Furthermore, Salter (1995) argued that relative performance measures appropriate surrogates for objective measures in the single-industry sample.

Wing (2000) stated that there are two major fundamental financial management tools which include budgets and variance analyses. Nevertheless, the reports of variance are not necessarily useful for a manager. When performing variance analyses, the main difficulty is that there is need for cost to be known as either as variable or fixed cost. Practically, large numbers of costs do not perform in this manner. It leads to constraints on reports and inadequate management behaviour. The author opined that financial managers must develop models that will reflect the way cost actually perform, and reporting the difference through improved cost models. When a system is based on an inadequate model, this can be used or discarded. But when it is used, it leads to inadequate decisions by the management.

Cokins (2002) stated that companies needs to be equipped with accurate cost modelling procedure so as to manage their costs and ascertain an acceptable profit margin. However, as competition grows larger, the origination of new products must outdo product becoming old or out fashioned. Production of a product that has been produced can be accomplished through reduction of unfavourable cost differences from the product's standard cost and applying advancement process and managing the cost. 
Morgan (2012) suggested that business performance consists of two aspects: market performance and financial performance. Market performance relates to customer behaviors. Higher sales volume, customer satisfaction increases, customer loyalty, and growth of market shares are indicators of market performance while the financial performance is measured in accounting terms. This study defines firm performance as a goal achievement and financial performance that are indicated by the net income goal achievement, sales amount and market share increases, the better return on investment, and the growth and continuance of overall performance

Siyanbola and Raji (2013) carried out a study on the The Impact of Cost Control on Manufacturing Industries' Profitability. the study was concentrated on West African Portland Cement Plc (WAPCO), where cost control was viewed from a strategic perspective. Pearson correlation model was used in analysing the data and the hypotheses tested confirmed positive impact of cost control on the industries' profitability. From the findings of this research, it is evident that cost control has a positive impact on business profitability and that element of cost, such as materials, labour and overhead cost and workers' behaviour could be strategically controlled with measures like responsibility accounting, data collection and data reporting.

Cletus and ThankGod (2015) investigated the relationship between standard costing and cost control in Nigerian oil and gas industry. This was achieved through a review of extant literature and development of hypotheses. The population for the study consisted of petroleum marketing companies listed in the Nigerian Stock Exchange Factbook of 2012. In order to generate the necessary data for this study, both primary and secondary methods of data collection were adopted. The primary data were collected through the administration of a questionnaire designed in a 5-point Likert scale, while the secondary data were sourced from the Nigerian Stock Exchange Factbook of 2011. The findings generated in this study revealed that a significant relationship exists between standard costing and cost control. It was observed that the more a firm practices standard costing, the more efficient is the firm in material, labor, and overhead costs. Based on the above findings, we recommended that oil and gas firms in Nigeria should adopt and apply standard costing in their accounting system so as to ensure the efficient use of resources for an effective control of costs

Sadiq, Iyanuoluwa, Mohammed and Faruk (2016) studied the effect of standard costing on profitability of telecommunications companies. The design of this paper is descriptive survey method and the paper was conducted at MTN Company, Kano which is the case study of this paper work. The instrument of data collection was analyzed using the chi-square method. The following were discovered findings show that accounting records are kept and are significantly necessary in the management of the company. That the company employs standard costing in their product and decisions are made with the standard costing information obtained in the company. That accounting reports are prepared and presented to the company's management and that actions are taken promptly on the information given in the report. That effective application of standard costing has effect on the profitability of the company. That the company benefit in a significant way through the use of standard costing especially in the improvement of profit. We came to a conclusion that standard costing is widely used in Nigerian telecommunication companies and that standard costing enhances adequate planning, control and decision making processes in the company. That standard costing aids telecommunication companies in the elimination of unprofitable products, provision of costing information and cost control.

Lawal (2017) aims to critically examine and evaluate the application of cost control and cost reduction in organizational performance and also to review the budget as an effective tool of cost control and cost reduction. A descriptive survey research was adopted. A total number of 50 questionnaires were administered and used for the study. The analysis of data collected was undertaken by applying appropriate statistical tools. Regression analysis was used to test the hypothesis with the use of SPSS. Based on the findings, it was evident that cost control has a positive impact on organizational performance and also the style of management has a positive impact on organizational performance.

\section{METHODOLOGY}

This study was conducted in Benin City, Edo state of Nigeria. This choice was prompted by the high level of manufacturing activities which abound in the state, more specifically Benin City, Edo state. The study adopted survey research design. Five (5) point Likert scales were used to analyze the questionnaire. The population of the study is made up of the total staff of production departments and accounting departments of the selected companies below; Guinness Nigeria Plc 34, Integrated Rubber Products Nigeria Plc 29, Livestock Feeds Plc.22, Nigeria German Chemicals 27, Niki Manufacturing Company Ltd 19.

Simple random sampling was adopted in this study. Since the population is finite, Taro Yamane formula for sample size determination was used to determine the sample size as shown below;

$\mathbf{n}=\mathrm{N} / 1+\mathrm{N}(\mathrm{e})^{\wedge} 2=131 / 1+131(0.05)^{\wedge} 2=131 / 1+131(0.0025)=131 / 1+0.3275=131 / 1.3275 \mathbf{n}=99$

$\mathbf{n}=$ sample size, $\mathbf{N}=$ Population size, $\mathbf{e}=$ error term

The statistical tool used in hypotheses testing is $Z$-test method. Z-test is a parametric statistic used to test significance of difference or relationship between two populations mean.

The $\mathrm{Z}$-test formula is 
$Z=\frac{x^{-}-\mu}{s / \sqrt{u}}$ Where $\bar{x}=$ Sample mean,

$\mu=$ Population mean

$\mathrm{n}=$ Sample size

$n-1$ = Degree of freedom

Decision Rule: for the Z-test accepts the null hypothesis when the alpha value is less than the probability values, otherwise we reject.

\section{DATA ANALYSES AND DISCUSSION}

Analysis of the data using statistical package for scientific studies (SPSS version 21)

Level of significant $=\mathbf{0 . 0 5}$

4.1 Test of Research Hypotheses

4.1.1 Testing of Hypothesis I

Ho: Standard costing has no significant effect on cost reduction

Table4.1. Descriptive Statistics

\begin{tabular}{|l|l|l|l|l|l|}
\hline & $\mathrm{N}$ & Mean & Std. Deviation & Minimum & Maximum \\
\hline Standard costing & 5 & 16.0000 & 12.10372 & 4.00 & 32.00 \\
\hline
\end{tabular}

Source: SPSS Output

Table 4.2. One-Sample Kolmogorov-Smirnov (Z-Test)

\begin{tabular}{|ll|r|}
\hline & & Standard costing \\
\hline $\mathrm{N}$ & & 5 \\
Normal Parameters ${ }^{\mathrm{a}, \mathrm{b}}$ & Mean & 16.0000 \\
& Std. Deviation & 12.10372 \\
Most Extreme Differences & Absolute & .218 \\
& Positive & .218 \\
& Negative & -.161 \\
& & .488 \\
Kolmogorov-Smirnov Z & & .0011 \\
Asymp. Sig. (2-tailed) & &
\end{tabular}

a. Test distribution is Normal.

b. Calculated from data.

From the analysis above, it shows that the probability value $(0.011)$ is less than the alpha value $(0.05)$, the researcher therefore rejects the hypothesis no significant effect on cost reduction.ion.

\subsubsection{Test of Hypothesis II}

Ho: There is no positive effect of standard costing on gross profit.

Table 4.3. Descriptive Statistics

\begin{tabular}{|l|l|l|l|l|l|}
\hline & N & Mean & Std. Deviation & Minimum & Maximum \\
\hline Standard costing & 5 & 16.0000 & 16.91153 & 2.00 & 44.00 \\
\hline
\end{tabular}

Source: SPSS Output 
Table 4.4. One-Sample Kolmogorov-Smirnov (Z- Test)

\begin{tabular}{|ll|r|}
\hline & & Standard costing \\
\hline $\mathrm{N}$ & & 5 \\
Normal Parameters ${ }^{\mathrm{a}, \mathrm{b}}$ & Mean & 16.0000 \\
& Std. Deviation & 16.91153 \\
& & .253 \\
Most Extreme Differences & Absolute & .253 \\
& Positive & -.204 \\
& Negative & .566 \\
Kolmogorov-Smirnov Z & & .004 \\
Asymp. Sig. (2-tailed) & &
\end{tabular}

a. Test distribution is Normal.

b. Calculated from data.

Also the analysis shows that the alpha value $(0.05)$ is greater than the probability value $(0.04)$ of the second hypothesis; the Researchers therefore reject the null hypothesis of no significant effect of standard costing on gross profit.

\subsubsection{Test of Hypothesis III}

Ho3: standard costing does not have significant effect in reduction of normal losses.

Table 4.5. Descriptive Statistics

\begin{tabular}{|l|l|l|l|l|l|}
\hline & N & Mean & Std. Deviation & Minimum & Maximum \\
\hline Standard costing & 5 & 16.00 & 12.49000 & 5.00 & 35.00 \\
\hline
\end{tabular}

Source: SPSS Output

Table 4.6. One-Sample Kolmogorov-Smirnov (Z-Test)

\begin{tabular}{|ll|r|}
\hline & & Standard costing \\
\hline $\mathrm{N}$ & & 5 \\
Normal Parameters ${ }^{\mathrm{a}, \mathrm{b}}$ & Mean & \\
& Std. Deviation & 16.0000 \\
Most Extreme Differences & Absolute & 12.49000 \\
& Positive & .256 \\
& Negative & .256 \\
Kolmogorov-Smirnov Z & & -.189 \\
Asymp. Sig. (2-tailed) & & .571 \\
\hline
\end{tabular}

a. Test distribution is Normal.

b. Calculated from data.

The analysis also shows that the probability value (0.009) of the third hypothesis is less than the alpha value (0.05), the researchers therefore reject the null hypothesis that standard costing does not have significant effect in reduction of normal losses.

\subsection{Summary of Findings and conclusion}

This study investigated the effect of standard costing on profitability of selected manufacturing companies. Findings reveal that standard costing has significant positive effect on cost reduction and on gross profit. Furthermore, the study reveals that standard costing has significant effect in reduction of normal losses in the manufacturing processes. It is concluded that standard costing has significant positive effect on profitability of manufacturing companies that have it in practice. The implication is that standard costing works effectively as cost control technique and that elements of manufacturing costs (materials labour and overhead) can be strategically controlled with standard costing system to achieve organizational profitability through cost reduction and minimization of wastages and production process losses. 


\subsection{Recommendations}

1. All Manufacturing firms should adopt standard costing technique to enhance their profitability especially in the present economic 'tight corner'.

2. The Management of firms should endeavour to communicate management plans with respect to standards and plans to prevent resistance.

3. Standard costing should be accompanied with proper record keeping monitoring variances over time to enhance management by exception.

\section{REFERENCES}

Adeniji, A. A. (2009). Cost Accounting. A Managerial Approach. Lagos State, Nigeria: El- Toda Ventures limited publishers.

Athanasoglou, PP, Delis ,MD \& Staikouras, CK(2006). The determinants of bank profitability in the South Eastern European Region, MRPA Paper No.10274.

Cletus O. A. \& Thankgod C. A. (2015). Standard Costing and Cost Control in Nigerian Oil and Gas Industry. Journal of Modern Accounting and Auditing, 11(4), 185-193 doi: 10.17265/1548-6583/2015.04.001.

Cokins, G. (2002). Integrating target costing and ABC. Journal of Cost Management, 22-29

Dean, J. (1948). Cost structures of enterprises and break-even charts. The American Economic Review, 38(2), $153-$ 164

Egbunike, P.A. (2007). Management accounting techniques and applications. SCOA Heritage Nigeria Ltd. ISBN: 978-97852716-3-8.

Eyisi, S. A. (2009). Cost Accounting: Theories and Practice. Enugu. Ayi- best Publishers.

Guardian Newspaper. www.ngrguardiannews.com Accessed. 28/7/2018

Lawal, B. A. (2017). Effect of Cost Control and Cost Reduction Techniques in Organizational Performance. International Business and Management,14(3)19-26 DOI:10.3968/9686.

Lucey, T. (2002). 6th edition, Costing. New York: Biddles Limited, Guildford and King’s Lynn.

Morgan, Neil, A. (2012). Marketing and business performance. Journal of the academic Marketing science.

Pandey, I. M. (2010). 10th Edition, Financial management.. New Delhi: UBS Publishers Distributors Pvt Ltd.

Reeve, J. M., \& Philpot, J. W. (1988). Applications of statistical process control for financial management. Journal of Cost Management (fall), Master of Accounting Program, 33-40

Sadiq, R. A.; Iyanuoluwa O.; Muhammed, D. A., \& Faruk I. S. (2016). Effects of Standard Costing on the Profitability of Telecommunication Companies. Information and Knowledge Management ISSN 2224-5758 (Paper) ISSN 2224-896X (Online) 6(8).

Slater, S. F. (1995). Issues in conducting marketing Strategy research. Journal of strategic marketing.

Siyanbola, T. T. \& Raji, G. M. (2013). The Impact of Cost Control on Manufacturing Industries' Profitability. International Journal of Management and Social Sciences Research (IJMSSR) 2(4). April.

Wing, K. T. (2000). Using enhanced cost models in variance analysis for better control and decision making. Management Accounting Quarterly, 27-35

Yoshikawa, T. J., Innes, J., Mitchell, F., \& Tanaka, M. (1993). Contemporary cost management. London, UK: Chapman and Hall 